P\&A Año 3, N. ${ }^{\circ} 4$

enero-junio 2018

pp. [5]-15

\title{
Resumen
}

Partiendo de una reflexión crítica sobre cómo abordar el entendimiento de la "arquitectura andina" como dinámica social, se intenta esbozar un perfil teórico y metodológico aplicable en el campo del conocimiento interdisciplinario entre la arqueología, la arquitectura y la antropología, y de la misma manera se pretende ordenar algunos aspectos básicos inherentes a ella y a sus particularidades estéticas e históricas que resultan útiles en el estudio académico. Finalmente, se expondrán las pautas de la experiencia didáctica dentro de un contexto universitario.

Palabras claves: Arquitectura andina, arqueología andina, historiografía, territorio, pedagogía de la arquitectura.

\section{Miradas interdisciplinares. Una introducción al estudio de la arquitectura arqueológica*}

\author{
Interdisciplinary looks. An introduction to the analysis of archaeological architecture
}

\author{
Arq. Miguel Guzmán Juárez $z^{\star \star / ~ J o r g e ~ A l v i n o ~ L o l i * * * ~}$
}

Recibido: 21 de agosto de 2017

Aceptado: 18 de abril de 2018

\begin{abstract}
Starting by a critical reflection on how to deal with the understanding of "Andean architecture" as a social dynamics, it tries to outline a theoretical and methodological profile applicable to the field of interdisciplinary knowledge among archeology, architecture and anthropology, and likewise it is intended to order some basic aspects inherent to it and its aesthetic and historical particularities that may be useful in academic study. Finally, the guidelines of the teaching experience within a university context will be shown.
\end{abstract}

Keywords: Andean architecture, Andean archeology, historiography, territory, architecture pedagogy.

* El presente artículo se basa en una reflexión crítica acerca de la enseñanza de la historia de la "arquitectura andina", a partir de las investigaciones realizadas por los autores sobre diferentes sitios arqueológicos con la participación de los estudiantes. Se trata de una parte de un estudio mayor sobre la arquitectura andina que incluye las dimensiones de la creación arquitectónica (planificación, diseño y construcción), la investigación científica y, el aprendizaje aplicado.

** Arquitecto por la Universidad Ricardo Palma. Magíster en Arqueología Andina por la Universidad Nacional Mayor de San Marcos. Candidato a Doctor en Ciencias Sociales, mención en Antropología, por la misma universidad. Docente en las Facultades de Arquitectura de la Universidad Ricardo Palma, Universidad Peruana de Ciencias Aplicadas. Contacto: quillca@hotmail.comde edificaciones residenciales, consultoría en el área de planificación; docente del área de urbanismo de la Universidad Ricardo Palma.

*** Graduado por la Facultad de Arquitectura y Urbanismo de la Universidad Ricardo Palma. Graduado por la Facultad de Ciencias Sociales en la especialidad de Arqueología de la Universidad Nacional Mayor de San Marcos. Estudios de Maestría en Conservación del Patrimonio Edificado en la Universidad Nacional de Ingeniería (UNI), Maestría en Museología y Gestión Cultural en la Universidad Ricardo Palma (URP), y Maestría en Historia del Arte Peruano en la Universidad Nacional Mayor de San Marcos (UNMSM). Ha ejercido docencia en la UNMSM, Universidad Peruana de Arte Orval y en Talleres de Capacitación Docente del Instituto Nuevos Tiempos. Contacto: jc_alvino@hotmail.com 


\section{Introducción}

Lydia Fossa, en su Narrativas problemáticas, es contundente al señalar sus primeras conclusiones a partir del riguroso estudio que realiza acerca de los primeros cronistas, desde los cuales generalmente se asumió y se ha construido la "Historia del Perú", indica que dichos textos "son versiones de una parte de la historia de los españoles en los Andes, y no la historia del Perú." (2006, p.497). Ello, que podría considerarse algo tan obvio "no fue tomado en cuenta por quienes redactaron los textos de nuestra historia que hasta hoy se leen en colegios y universidades."(curnia). De modo similar, se podría argumentar que la historia en general ha sido construida a partir de una visión occidental, con una estructura unilineal y con sustentos que privilegian externalidades desde un entendimiento idealizado de lo estético en su acepción de belleza. La "tradición occidental" ha marcado un recorrido de dependencia cultural — de hegemonía frente a los otros-que fue sustentado desde los primeros contactos con América bajo el estigma de la superioridad de la escritura, frente a un sistema "mágico" de símbolos (primera contradicción: el desencuentro de la comunicación). Al mismo tiempo, la empresa de la invasión española, de carácter netamente económica, quiso imponer la religión católica como sustento por medio de una evangelización feroz, que debió recurrir a la extirpación de "idolatrías" (segunda contradicción: la paradoja de la fuerza del bien).

El acercamiento al conocimiento arquitectónico, y luego a su reconocimiento, de lo "andino", está cargado aún de ciertos estereotipos que enfatizan las formas de los edificios, la de los asentamientos o de los referentes territoriales, muchas veces ligado a ciertas ilusiones figurativas y a un aura de energía mís-

\footnotetext{
1 David Sobrevilla inaugura la idea de cuestionar el estado de las cosas, de repensar la producción, en tanto filosofía que propone replantear aquello asumido como una tradición, sobre todo de aquella "tradición occidental" de pretensión universal. Publicó en 1986 Repensando la tradición Occidental. Luego, en 1989 Repensando la tradición nacional. Estudios sobre la filosofía reciente en el Perú, y en 1999 Repensando la tradición de nuestra América.
}

tica percibida en clave turística. Esa manera superficial de entender va de la mano con ciertos discursos "pedagógicos" verbalizados con categorías conceptuales que se alejan de las particularidades del territorio andino. Lo que se presenta es, por lo tanto, una reflexión acerca de esos procesos de acercamiento hacia la complejidad del fenómeno de la arquitectura, proponiendo una mirada necesariamente interdisciplinar, para acercarse luego a una discusión epistémica sobre la pedagogía de la arquitectura arqueológica y sus diversos conflictos o tensiones conceptuales, para finalmente tratar de esbozar una metodología práctica a partir de ciertas experiencias, que en el fondo pretenden contribuir a la interpretación de la arquitectura como dinámica social, como reflejo de las estructuras y los modos de vida de aquellas antiguas sociedades. Se trata entonces de repensar la arquitectura andina desde una idea crítica de la sociedad contemporánea y desde sus formas de enseñanza.

\section{De la tradición occidental a la idea crítica de lo andino}

En la historia de la arquitectura, algunos episodios parecen articularse con el estudio de la arqueología. Resulta inevitable mencionar como primer elemento el clásico paradigma documental sobre el inicio de la producción teórica de la arquitectura, construida desde occidente a partir del redescubrimiento de la obra escrita por Vitruvio (siglo I a.C.), conocida como Los diez libros de la Arquitectura $(1995)^{2}$, reimpresa en Roma hacia 1470. El pensamiento de Vitruvio es tan poderoso que atraviesa los siglos, influye en Occidente a través del Renacimiento y sobrevive al

2 Los Diez Libros de la Arquitectura (De Architectura librum decem) fue escrito por Marco Lucio Vitruvio Polion, hacia las primeras décadas del siglo I a.C., probablemente entre los años 27-23 a.C. Es una suerte de documento fundacional para la tradición arquitectónica de occidente. Ludeña señala que es "el pilar histórico del cuerpo ideológico que encarna esta cultura en materia de arquitectura y construcción, y que se hizo dominante en América a fuerza de violencia y de 'extirpar idolatrías' con la ayuda de la biblia cristiana y de las otras un poco más profanas pero no menos esenciales, como el celebérrimo tratado de Vitruvio." (1997, p.7). 
proceso europeo y a la difusión de ideas hacia América, teniendo un alcance temporal y simultáneo al desarrollo del mestizaje, que en cierta forma configura desde allí parte de la identidad del arquitecto contemporáneo. A partir del impulso humanista del Renacimiento se desarrolló también un nuevo significado acerca de los antiguos edificios (en este caso romanos) como objetos de contemplación y reflexión. Roma había sido modelo de ciudad imperialista, pero después de su caída (476 d.C.) permaneció en ruinas y sus monumentos más grandes estaban enterrados, incluso el Foro, que fue llamado en los siglos siguientes Campo Vaccinio ("campo vacuno"), fue lugar de extracción de material para construcciones durante el siglo XIV. Algunos artistas lo visitaron a fines del siglo XV para dibujar en sus ruinas, siendo recién en 1515 cuando el Papa León X nombró a Rafael como Superintendente de Antigüedades de Roma, pudiéndose al menos hacer inventarios o darles alguna protección.

En Florencia de inicios del siglo XV, se da el segundo episodio con el impulso del Renacimiento. Filipo Brunelleschi (1377-1446 d.C.) logró a través de la adaptación del arte romano local, un replanteo de la concepción de la arquitectura, y con León Battista Alberti (1404-1472 d.C.) — con su De Re Aedificatoria (El arte de edificar, 1485) - se afirmaron las bases intelectuales de la Arquitectura, considerada para entonces como un "arte mayor" y pieza maestra del Humanismo, que tendría como un principio fundamental el conocimiento y la interpretación de la antigüedad. La concepción de la arquitectura clásica, la estética renacentista y el estudio de los monumentos de la antigüedad, dieron código a la "profesión" de arquitecto, exigiendo que éste sea letrado, con conocimientos de dibujo, geometría, física, música e historia. Así, la actividad arquitectónica, tal como lo planteó en Occidente (y América a partir de su influencia) va a referirse en una de sus dimensiones a imágenes reportadas desde su pasado, un pasado asimilado como propio, pero también como actual y contemporáneo al aplicarse dicho repertorio a las obras construidas dentro de un espacio cultural como lo es la ciudad y asimilándose a la interpretación colectiva urbana. Esta aparición de formas de la antigüedad, sin duda, estuvo acompañada de la admiración por parte de un grupo de intelectuales que la conocía de textos heroicos y tradiciones de pensamiento que comenzaban a ser valoradas. Las edificaciones provocan un potencial creativo que ya se encontraba despierto. No es una fuente de copia, sino el componente necesario para fundamentar la creación de un nuevo ser: el "yo artista".

Un tercer momento fue la difusión de los trabajos en Pompeya y Herculano. Se sabía la suerte que habían corrido ambas ciudades por la erupción del volcán Vesubio (79 d.C.), sin embargo, recién causaron sensación al ser descubiertas al público: Herculano en 1738, y Pompeya en 1748 (posiblemente en 1550 el arquitecto Fontana ya las había ubicado) y a partir de los trabajos de excavaciones y restauraciones, la imagen arquitectónica de una ciudad proveniente del pasado llamó la atención mundial. En ese contexto, Winckelmann (1717-1768) señaló un retorno teórico al "mundo clásico". Había trabajado en el Vaticano y pudo participar en las obras de Pompeya y Herculano, recuperando a partir de lo romano el ideal utópico de la sociedad helénica conceptualizado en el término kalokagathia, que hace referencia simultáneamente a las nociones de lo bueno, lo bello y lo verdadero. A partir de su obra Reflexiones sobre la imitación de las obras griegas en la pintura y la escultura (1755) es considerado uno de los precursores de la "historia del arte" y la "arqueología". La influencia e inclusión de los edificios antiguos a veces será considerada como un entorpecimiento del progreso, pero en otras ocasiones servirá de inspiración y fortalecerá el espíritu de las naciones.

En el caso andino, habría que preguntarse acerca de cuál es la tradición arquitectónica desarrollada autónomamente y sostenida conceptualmente dentro de su propio sistema de pensamiento. Sin embargo, también hay que comprender que el "encuentro" cultural con occidente fue ruptura y desestructuración, pero no eliminación ni olvido, sino un 
proceso complejo de mestizaje y sincretismo ${ }^{3}$. En ese sentido, la tradición andina no se agota en el siglo XVI, sino que explora campos de recreación que pueden ir desde lo lúdico hasta lo surrealista. Obviamente, no hubo una tratadística en el sentido occidental del discurso, pero sí un sistema de pensamiento que cada vez más se está reelaborando a partir de los avances de la etnohistoria. Por ejemplo, desde mediados del siglo pasado, o desde la propia arqueología. Este "sistema de pensamiento andino" está presente aun en los lenguajes, en toda la elaboración material e iconográfica de la arquitectura y de los objetos y si se quiere, en las formas de ocupación del territorio. Para evitar conflictos con Occidente, parece pertinente no hablar de "filosofía andina"4 sino de "pensamiento andino". Víctor Quiroz lo define como el "modo particular de la sociedad andina de racionalizar y conceptualizar la realidad", hundiendo sus huellas en el pasado ancestral, pero que dicho pensamiento hasta la actualidad "no se ha mantenido como núcleo 'esencial' o 'incontaminado', [...sino que] ha permanecido en forma de principios cognoscitivos que se actualizan en las distintas prácticas socioculturales de la comunidad andina." (Quiroz, 2011, p.14, cursiva agregada). Sobrevilla había señalado "que en un sentido estricto la filosofía es un producto griego y occidental" (1999, p.13), cuyo sustento sería lo racional y su pretensión de ser universal. Por ello aboga

\footnotetext{
3 Se entiende por sincretismo el proceso y resultado del encuentro cultural de dos sistemas religiosos diferenciados. De manera específica, Manuel Marzal señala que a partir de ese contacto prolongado pueden ocurrir tres procesos: síntesis cuando se funden en una nueva religión, yuxtaposición cuando cada una retiene su identidad superponiéndose, y sincretismo cuando se integran en una nueva, pero diferenciándose los orígenes de cada una. (Marzal 2002, p.108). De manera parecida, aunque abogando por superar el término, Manuel Gutiérrez indica que se debería sustituir "por el esfuerzo para entender las diversas formas de conectividad entre los fragmentos heterogéneos y ajenos que los pueblos indígenas, en un proceso histórico continuo, incorporan a su «enciclopedia» cultural." (Gutiérrez 2013, p.505).

4 A pesar de ello, existe un libro controvertido que apuesta por enfatizar en la existencia de una Filosofía andina (Estermann, 1998), partiendo de la necesidad de una "filosofía intercultural" que promueva el diálogo múltiple, una suerte de "polílogos".
}

por la diversidad, indicando que la filosofía es solo una forma o "un tipo de orientación en el mundo", y que, en todo caso, la orientación del mundo en las sociedades tradicionales estaba estructurada sobre la base de los mitos, la religión, las costumbres, las prácticas o los rituales (ibid, p.12), es decir, una cosmovisión mística, simbólica o sacralizada de la existencia. Esta cosmovisión es una forma de pensamiento, y cada "forma de pensamiento significa una forma de comprensión total del mundo equiparable a los otros." (Sobrevilla, 1999, p.55)

Para tener una visión integral del proceso, habría que señalar ciertos olvidos y ciertas memorias en la historiografía andina. El primer "olvido" dirigido — aunque nunca total- fue aquella entronización del mundo hispano sobre el nuevo continente y los cambios en las formas de la estructuración espacial con la consiguiente creación de "pueblos" diferenciados. Luego de siglos de rebeliones y luchas, el inicio de la República marcó una nueva ruptura, un paradójico silenciamiento y un segundo olvido por lo autóctono o lo “indígena”. La independencia significó nuevas formas de dependencia y la aceptación de otros colonialismos velados por el desarrollo de lo económico y los inicios de cierta modernidad. Ello se expresó en una concentración y una centralización a manera de un cerco ilusorio del poder desde la capital con un profundo olvido por el resto de los pueblos del territorio andino, que señalaron una ruptura y una marginación entre las regiones. Se construyó una historiografía oficial desde el poder.

Frente a un estado de cosas ilusorias, impuesto desde arriba, donde lo que prima es la inexistencia del pasado, los movimientos culturales que se iniciaron hacia la segunda década del siglo XX, dentro de las distintas vertientes del nacionalismo fueron construyendo un segmento cultural importante que se expresa contemporáneamente en las variadas ideas por "repensar" lo "andino", con lo problemático que podría ser definir el nombre o concepto más apropiado para este territorio caracterizado físicamente por su 
cordillera. La memoria yuyay, para la redefinición de la historiografía andina, podría plantearse a partir de un estudio riguroso de los aportes dados sobre cinco grupos o momentos: los cronistas, los extirpadores de idolatrías (fines del siglo XVI e inicios del XVII), los viajeros (de los siglos XVIII y XIX), los primeros atisbos de la arqueología (fines del siglo XIX), y los nacionalismos del siglo XX, expresados en el indigenismo, en los descubrimientos arqueológicos, en la política y el socialismo peruano de Mariátegui, y en las propuestas formales y reflexivas de la arquitectura (neocolonial, neoinca o neoandina y neoperuana), desde los cuales, los etnohistoriadores y la renovada arqueología científica, desde mediados del siglo pasado, están reescribiendo las dimensiones integrales de las antiguas sociedades andinas. Junto con ello, y con el influjo de los movimientos estudiantiles se cuestionan los fundamentos mismos de la nación y su trayectoria, una mirada crítica hacia el pasado. Esta "idea crítica" se ha ido configurando hace algunas décadas, y evalúa el discurso oficial, propuesto desde arriba por el Estado, y todo aquello que se agota en una narración historiográfica oficial, que presenta el esquema de "fechas-personajes-acontecimientos" (Portocarrero y Oliart, 1989, p. 108). La mirada actual sobre el pasado y sobre aquella arquitectura en particular necesita ser repensada desde adentro. Dentro de esta propuesta reflexiva de reordenamiento del pasado andino y su trayectoria contemporánea habría que señalar también el aporte fundamental de Alberto Flores Galindo (1987), quien agudamente critica la idealización de lo andino en su vertiente "inca" y, asimismo, el olvido de ese personaje construido, casi indefinido, que significaría lo "indígena". Indica como una característica indiscutible e insustituible del siglo XX, eso que Basadre

5 Portocarrero y Oliart han propuesto el concepto de "idea crítica del Perú" (1989, pp.104-108) al movimiento intelectual que parece gestarse a partir de la década de 1960, básicamente desde las universidades estatales, y que se sustenta en una crítica y reflexión de la "historiografía oficial" que ha marginado la "participación popular" y ha percibido al sector "criollo mestizo" como símbolo de la peruanidad, señalando que lo que se busca es una nueva lectura de la realidad. había señalado: la toma de conciencia sobre la existencia del "indio", irónicamente se podría decir, es un descubrimiento en clave arqueológica de este personaje casi exótico. En esos conflictos tensionales se ha recreado la "utopía andina"

\section{Miradas interdisciplinares}

Esbozar una pedagogía de la arquitectura andina y su reconocimiento, debe partir de la reflexión sobre el lugar, sobre las persistencias, continuidades y transformaciones de los sistemas de pensamiento en general y, de los patrones de asentamiento y las tipologías arquitectónicas, así como de los modos de producción-construcción de manera particular. La enseñanza de la arquitectura debe tener un carácter multidisciplinar, tal como es y está dándose en las investigaciones de los diferentes proyectos arqueológicos.

En ese orden de cosas, se debe repensar y superar ciertos vacíos en una suerte de concienciación ${ }^{7}$ integral de lo múltiple. Mirar el pasado como lo hace la arqueología, cuyo objeto de estudio es la evidencia fáctica, y su objetivo final es la comprensión de las dinámicas sociales y sus transformaciones, genera una pauta de la temporalidad y de los cambios, generalmente prolongada, pero que lamentablemente en la arquitectura muchas veces se ha simplificado a una esquematización o tipificación formal que no distingue aquellos micro procesos. En esta especificidad de la arqueología, parece fundarse, sostenerse y camuflarse la idea del "patrimonio" que diferencia lo arqueológico de lo histórico. Esto, difundido en las escuelas de arquitectura confunde y genera prejuicios, que en el

6 "La idea de un hombre andino inalterable en el tiempo y con una totalidad armónica de rasgos comunes expresa, entonces, la historia imaginada o deseada, pero no la realidad de un mundo demasiado fragmentado. La utopía andina son los proyectos (en plural) que pretendían enfrentar esta realidad." (Flores Galindo, 1987, p.18).

7 "La idea de un hombre andino inalterable en el tiempo y Paulo Freire, se refiere a la "concienciación", como un proceso desde abajo e inclusivo y no una imposición, "no solo es conocimiento o reconocimiento, sino opción, decisión, compromiso." (Freire, 1976, p.5) 
fondo siguen haciendo referencia a la primera contradicción anotada, donde se ha sobreevaluado el poder de la escritura (historia), de tal manera que lo arqueológico es visto como apéndice o como un pasado exótico ligado a la idea de museo-almacén.

Otro aspecto dejado de lado, soslayado y exotizado es el de los idiomas. Recién en las últimas décadas se ha tomado conciencia acerca de la existencia de los denominados "pueblos indígenas" o "pueblos originarios", que poseen y son portadores de una carga ancestral rica en las diferentes expresiones culturales, y están formando parte de los colectivos sociales que apuntan a consolidar la diversidad, lo múltiple y lo identitario. Pero la pregunta sería ¿cómo conocerlos realmente si se desconoce su idioma, su lengua y la riqueza de conceptos dentro de su sistema de pensamiento? Los aportes de la lingüística son entonces significativos para hilvanar palabras-ideasconceptos que se acerquen a una relación más cercana con los sitios arqueológicos, sus edificios y los referentes del territorio, que en muchos casos guardan aún por toponimia nombres cargados de significados, que estarían generando nuevas narraciones espaciales. La pedagogía de la arquitectura debe preocuparse por la comprensión de los idiomas, que contribuya a un reconocimiento del porqué de los determinados diseños o de las organizaciones espaciales realizadas. Algunas categorías conceptuales del pensamiento andino hacen referencia implícita a un manejo organizado del espacio, es decir, se postula que serían categorías espaciales referidas también a la arquitectura, a la planificación, al manejo del territorio y al diseño de los asentamientos y edificios. Por ejemplo, dentro de la categoría espacial los conceptos: eje ceque, simetría yanantin, centro chaupi, lugar de encuentro tinkuy, círculo muyuc, así como las referidas a la dualidad arriba-abajo hanan-urin o a la tripartición afuera-aquí-adentro hanaqkay-ucku pacha respectivamente, o para la categoría temporal, los conceptos de: futuro (atrás)-presente (aquí)-pasado (adelante) quipa-kai-ñaupa, o el de retorno cuti, están cargados de implicancias sugerentes para el manejo del diseño. Es decir, serían conceptos que aludirían a los procesos de diseño y construcción, ya que "las categorías de un sistema conceptual (...) no son indiferentes a ciertas categorías de su lengua", las lenguas poseen "ciertas categorías conceptuales capaces de organizar el mundo referencial." (Godenzzi, 2005, p.15).

Lo interesante es el acercamiento a las fuentes primarias, la comprobación de la existencia aun de una compleja arquitectura diseminada por todo el territorio andino genera un atributo potencial: la relación directa con los sitios es una experiencia, una clase y sobre todo una pedagogía sobre el manejo del lugar, del relieve y la construcción del paisaje. John Dewey, entre otras cosas, señalaba la importancia de la experiencia en la transmisión de los conocimientos y, aunque existe una importancia en los datos empíricos recogidos por las ciencias sociales es más importante aún una "actitud científica, entendida como: un espíritu abierto y comprensivo, libre de prejuicios dispuesto a poner siempre las ideas a prueba de la experiencia" (Elías, 2012, p.114). Dewey (1948) enfatiza la importancia de la experiencia en campo. La mejor manera de aprender una cosa es haciéndola, de esta manera el docente debe diseñar actividades y propiciar las situaciones en las que los alumnos tengan que experimentar. Es por ello que los trabajos, por ejemplo, de levantamiento de edificios por medio de cuerdas, pesos, varas, pasos, etc., y otras herramientas o técnicas andinas son imprescindibles, pues ponen en valor las técnicas originales, las dificultades medioambientales y, además, las logísticas no son menos importantes (por ejemplo, caminar de un lugar a otro o calcular físicamente el gasto de energía). Esto genera, que ante el acercamiento al hecho edificatorio en un contexto arqueológico, se provoquen nuevas expectativas. Es normal que se reproduzcan ciertas inseguridades ante una realidad que no es común en la praxis arquitectónica contemporánea, que está mediada por siglos o milenios, y que se considera parte del dominio de otra disciplina (la arqueología).

La nueva arqueología introduce una mirada científica a aquello que había sido visto como 
un conjunto de objetos recuperados, capaces de definir "culturas" por la presencia de una estilística y tipología formal interna, que podrían construir sistemas iconográficos para una lectura temporal del pasado. Los nuevos enfoques son muy diversos y tienen grados de complejidad instrumental y teórica que remiten a una reflexión constante de los procesos de producción social. En el fondo, hay una incidencia en comprender el contexto en el que se inscriben los sitios, una mirada holística, que lleva a postular una serie de especialidades afines entre sí, y de manera particular con el dominio de la arquitectura. Por ejemplo, la importancia que desarrolló desde la década de 1980 la "arqueología del paisaje", denominada también "arqueología espacial", o "arqueología contextual", y luego, la "arqueología de la arquitectura" como una especialización en la estructura edificatoria, o de manera más específica, tratando de comprender la dinámica de los flujos espaciales y su relación perceptual, la "sintaxis espacial". De allí la importancia de la mirada integral desde las relaciones con el emplazamiento hasta la construcción simbólica del paisaje. (Guzmán, 2016b) Se tiende a la integración con disciplinas que permitan una lectura del territorio, por ejemplo, desde la ecología humana que vincula al ser humano con su ecosistema. Patrick Geddes, impulsor de la ecología urbana, propuso sus tres clásicos elementos: lugar-trabajo-gente, que combinándose pueden caracterizar la dinámica entre el hombre y la naturaleza en una región determinada (Geddes, 1960). Fue retomado por Eduardo Neira, señalando que en "realidad estos tres elementos corresponden a los elementos biológicos de Ambiente-FunciónOrganismo. Ellos pueden, por otra parte, reconocerse formando parte de tres disciplinas modernas: Geografía, Economía y Antropología" (Neyra, 1962, p.21). Recientemente, la geografía viene reevaluando sus objetivos, y cada vez más se va ligando a un estudio de la dimensión física donde las comunidades participan activamente, el espacio geográfico es vívido, y ha tomado como reflexión medular y epistemológica los conceptos espaciales como lugar, territorio o paisaje, lo cual señala la necesaria y complementaria interdisciplinariedad (ver p.e. Souto (coord.), 2011; Ramírez y López, 2015).

\section{La arquitectura andina como dominio}

El estudio de lo que hoy se denomina edificio arqueológico ¿a qué disciplina corresponde? Existen áreas del conocimiento en donde la investigación alcanza cierto rigor científico que se hace necesario el trabajo interdisciplinario, áreas que aún están en proceso de construcción. Distinguir el dominio de cada disciplina es necesario para poder hallar estas áreas de interacción. De esta manera: "la necesidad de definir con precisión el 'dominio real' de aquello que puede ser designado con la categoría arquitectura (...) pasa necesariamente por la formulación previa de 'teorías regionales' sobre los distintos aspectos de este dominio de la arquitectura (el edificio, las ideas o los procesos)." (Ludeña, 2001, p.122). Es decir, se debe partir por establecer ciertas lógicas a partir del reconocimiento de la producción arquitectónica de cada sociedad, de todo su universo recreado en la construcción, en busca de elaborar y definir todo aquello que le es propio como el dominio referente a su materialización. Y, lo propio de la arquitectura es la construcción en sus tres niveles: la "arquitectura del paisaje"8 (como manejo y transformación del territorio), la arquitectura del asentamiento y la arquitectura del edificio. En este contexto, los "sitios" arqueológicos son los lugares en donde existe alguna evidencia cultural del pasado, generalmente asociados a alguno de los tres aspectos señalados. En buena cuenta y en un gran porcentaje, el estudio de la arqueología comprende también el análisis de la arquitectura, manifes-

8 En una reciente conferencia, referida al "paisajismo inca", José Canziani postuló la fórmula conceptual de "arquitectura del paisaje", para aludir a aquellas transformaciones de carácter utilitario realizadas sobre el territorio (terrazas, andenes, etc.), pero que en el fondo comprenden un manejo estético o plástico en su relación con el contexto. (Conferencia realizada en el Auditorio Fundación Telefónica, el 24.03.2018). Coincidimos con esta visión, en lo que hemos venido señalando como el nivel macro del proceso de la arquitectura, el del "manejo y transformación del territorio" que es finalmente una construcción del paisaje. 
tándose una estrecha relación entre ambas. Pero de inmediato aparece el cuestionamiento acerca de cuáles son esos elementos propios de la arquitectura, aquellos que permiten desarrollar eficientemente los diferentes procesos de la construcción. ¿Cómo se ejecuta el trazo inicial del edificio? ¿Hacia dónde se orientan los recintos? ¿Qué ejes espaciales se articulan con el contexto? ¿Cómo se definen las dimensiones de los espacios? o ¿Cuáles de los muros o recintos tendrían un diseño especial que podrían dar pautas de una relación necesaria con determinados eventos astronómicos? Son algunas interrogantes que desde la disciplina y el oficio de la arquitectura se podría interpretar.

Por otro lado, es interesante resaltar que existe una diferencia entre la arqueología andina y la europea. En esta última es llamada "prehistoria". En principio, ella se ha constituido después de muchos aportes de otras disciplinas como la geología, las ciencias naturales o la historia del arte, hacia inicios del siglo XX, y esto debido a la influencia de la antropología que introdujo Julio C. Tello, quien además contextualizó la disciplina en la realidad de un país sudamericano. De esta manera, la antropología, así como las fuentes carentes de escritura occidental, hacen que el estudio del pasado andino se sustente en el estudio de los materiales tangibles. En el caso de la arquitectura, esto deviene en el estudio de los edificios, pues acerca de las "ideas" o de los "procesos" no existe aún una sistemática o un corpus para identificarlos, o en alguna medida se perdieron en los primeros años del Virreinato. Es pues, el edificio de carácter arqueológico el punto de articulación de distintas disciplinas, y con mucho, el derrotero de la investigación arquitectónica sobre este pasado.

De aquí se desprende una preocupación: ¿cómo acercase a la arquitectura andina? De hecho, al llamarla así se le está atribuyendo una categoría formulada desde un punto de vista crítico referido a la dimensión de lo "andino". En este sentido, el concepto busca integrar y caracterizar un fenómeno cultural, término que se desliga de la connotación racista que sugiere la palabra "indio" o "indígena" y, asimismo, "evoca la idea de una civilización, no se limita a los campesinos sino que incluye a pobladores urbanos y mestizos" (Flores Galindo, 1987, p.12) y trasciende los límites, tanto internos incorporando costa, sierra y selva (lo andino-amazónico), como externos, incluyendo a los países por donde discurre la cordillera.

Se cree que se ha heredado una única identidad, cuando en los andes existió una diversidad (así como idiomas), se cree también en la construcción de una nación, cuando ese concepto (y sus componentes) es relativamente moderno, romántico y occidental, asimismo, que existió un "Perú Antiguo", cuando esa palabra correspondía a un solo personaje. De la misma manera, resulta insostenible dentro de la periodificación el concepto de lo "prehispánico" para referirse al desarrollo autónomo antes del contacto con Europa, ya que señala implícita y directamente la condición de dependencia o la construcción de una historia desde un origen foráneo. El dominio de la arquitectura andina implica un cuestionamiento, y para ello se nutre necesariamente de la arqueología (procesos, producción), la antropología (sistemas de pensamiento) y la propia arquitectura (diseño, construcción y configuraciones simbólicas), además de la etnohistoria, la lingüística, la geografía, la biología, así como de la astronomía, la geometría y las matemáticas, entre otras disciplinas. Más allá de la forma, se busca comprender la dinámica de la arquitectura en constante interacción social, espacial y temporal.

\section{Una aproximación a la metodología de la arquitectura arqueológica}

El objetivo es el aprendizaje de la arquitectura andina a través del acercamiento pedagógico y controlado, a los sitios y edificios de las antiguas sociedades, en tanto fuente primaria como objeto capaz de articular una narración de su pasado y presente, partiendo del análisis particular de las dimensiones de la arquitectura, del dominio propio y específico señalado. Allí se ha aludido a los tres niveles: territorio-paisaje, asentamiento y edificio, de tal manera que el primer compromiso es la 
contextualización en el espacio y en su tiempo histórico, generando el interés en la investigación arquitectónica, con la finalidad que los conocimientos "redescubiertos" puedan enriquecer el proceso creativo del estudiante. En ese nivel de análisis se ha propuesto también el reconocimiento de la cosmovisión a partir de: las estructuras de pensamiento, las estructuras de organización del espacio y del tiempo, y las estructuras de representación simbólica (Guzmán, 2003, p.31; 2016, p.62).

La primera etapa

Un primer objetivo corresponde a propiciar, alentar y gestionar la formación de grupo de trabajo, es decir, lograr que los estudiantes institucionalicen sus esfuerzos dentro de ámbitos académicos para lograr, mediante un método didáctico, el estudio y conocimiento aprovechable de la realidad arquitectónica de características arqueológicas. Los grupos de trabajo se integran por estudiantes universitarios con una base operativa mínima en trabajos de campo y uso de la información bibliográfica. Un segundo objetivo de estos grupos de trabajo es generar conciencia del patrimonio arquitectónico arqueológico a través del estudio de la sociedad andina. Estos estudios pueden darse en un primer momento en talleres o mediante charlas teóricas, lo relevante es provocar el acercamiento al contexto e importancia histórico social, a través de visitas guiadas y constantemente asesoradas por arqueólogos, arquitectos especializados y conservadores.

La segunda etapa

Un primer objetivo es el adiestramiento de lo que se considera como praxis "arqueo- arquitectónica", que es la experimentación en campo de un hecho edificatorio, es decir, un edificio arqueológico elegido de acuerdo a sus características intrínsecas, que permitan su lectura mediante una base mínima operativa de los estudiantes, la cual incluye el correcto relevamiento de planos arquitectónicos. Pero antes, este primer contacto con el "sitio" requiere un diálogo ritual de respeto y reciprocidad ante lo ancestral. Un segundo objetivo es el análisis de los documentos producidos, además de fotografías y aerofotografías, utilizando las lógicas de los procedimientos de construcción geométrica y física, así como su relación con los sistemas del territorio. Se intenta identificar procedimientos originales de diseño y construcción andina, además de sistemas de medida, gnómones y tipologías arquitectónicas. Un tercer objetivo es la recomposición arquitectónica de los edificios estudiados con el uso de isometrías, maquetas y escenificaciones, a partir del análisis. En este sentido es importante el desarrollo de las tecnologías virtuales de representación y modelación en $3 \mathrm{D}$, así como los diferentes equipos de teledetección remota para la obtención de datos en campo. El reconocimiento del territorio por medio de los Sistemas de Información Geográfica (SIG) junto con los programas de modelación tridimensional, forman parte de una revolución tecnológica que permite cierta rapidez, grados de precisión absoluta en el registro de detalles y mejores interpretaciones para una captura y visión integral que se acerca a la simultaneidad de la experiencia real. Sin embargo, y a pesar de esto, es necesario siempre la utilización de los esquemas y dibujos de detalles efectuados a mano, pues ahí se

9 El término "arqueo-arquitectura" fue acuñado por Alfio Pinasco hacia 1994, para referirse a los estudios desde la arquitectura que empezaban a realizar en el Santuario de Pachacamac. Se trata de un estudio interdisciplinario que busca conocer e interpretar la arquitectura arqueológica, con el apoyo de disciplinas como la arqueología, antropología, etnohistoria, astronomía, entre otras afines. En 1995 se funda el Instituto ArqueoArquitectura Andina (IAAA) con esta visión, en lo que hemos venido señalando como el nivel macro del proceso de la arquitectura, el del "manejo y transformación del territorio" que es finalmente una construcción del paisaje. 
produce una relación atenta y especial para la comprensión del hecho arquitectónico desde la percepción y la sensorialidad. Es decir, la observación directa que pretenda enfocarse luego a la reconstitución mental del edificio, en cuanto a forma y función. Incluso en el análisis de campo se pueden hacer observaciones que impliquen una hipótesis de cronología relativa (al margen de la documentación bibliográfica), estas pueden sustentarse debido a la observación de adosamientos, estratigrafía muraria, tipología de aparejos o elementos decorativos, y análisis de materiales entre otros, a partir del dibujo como registro documental.

\section{Conclusiones}

La arquitectura es una realidad compleja, concreta y dinámica, que se caracteriza por el uso diverso e intenso de sus espacios y por la interacción y los vínculos que se establecen allí entre las personas, los grupos o las comunidades. El estudio de la arquitectura en general, debe incorporar entonces una mirada interdisciplinar y, más aún, aquella producida por las antiguas sociedades andinas que debe tener presente, de forma particular, los criterios, pautas o teorías de las disciplinas afines como la arqueología y la antropología.

La tradición arquitectónica y urbana andina estaría signada por la ubicua presencia de la naturaleza sacralizada y la estructura cosmológica recreada simbólicamente cuyo sostenimiento vivencial se afianza socialmente con el sistema organizado de los calendarios rituales. En esta lógica se hace necesaria una sensibilidad especial, en el sentido de atención, asombro y comprensión, frente a aquello ciertamente ajeno en el tiempo. Comprender la arquitectura andina debe pasar por acercarse a ciertos vacíos narrativos o ciertos olvidos estructurados. Por ejemplo, desde las currículas de las facultades de arquitectura, o desde el tiempo que se le dedica a su estudio y acercamiento, en un territorio donde todo está ocupado de sitios-patrimonio, todo está por explorar, tan cerca y a veces tan lejos. Incluso, algunos paradigmas icónicos y arquitectónicos siguen siendo, para los estudiantes, los referentes de la "historia clásica griega". En reciente crítica de diseño, alumnos de mitad de carrera, comparando la organización espacial del Santuario de Pachacamac señalaron que allí "no existe un atrio como en el Partenón (...) y lo que se percibe es un desorden urbano". Ese imaginario racional e ilusorio está magistralmente representado en el Paseo de las Musas de Chiclayo, que busca construir una-otra identidad.

Ello implica repensar, ver la "historia" tal vez al revés, preguntándose, por ejemplo, cuál es la importancia de señalar el "norte" en los planos de los proyectos, si de lo que se trata es saber ver la orientación y el recorrido de los astros. Porqué incluso, siempre el mapa del territorio andino señala el norte para arriba, cuando ya desde la década de 1940, Joaquín Torres García, desde el arte, había propuesto su América invertida. En este sentido resultan interesantes las agudas publicaciones que desde diferentes disciplinas proponen "repensar" el estado de la historiografía (Sobrevilla, 1989; O’Phelan, 1999; Stein, 2010; Vega-Centeno, 2017). En el presente caso habría que "repensar la arquitectura andina", desde lo apropiado y pertinente evitando las marginalidades, y también desde lo complejo que resulta articular los discursos que se sustentan en ideologías, una promoción de lo múltiple, desde los idiomas y las religiones tanto como las arquitecturas regionales intensas y en constante recreación. Ello implica la elaboración de nuevas historiografías, narraciones, construcciones y retórica, además de códigos y símbolos desde lo andino. Acercarse a los edificios antiguos requiere también una cuota de respeto, cierta interiorización de lo otro, en el sentido de poseer en sus espacios y superficies una trayectoria temporal cargada de otredad, un cúmulo de conocimientos que posiblemente no se perciben directamente. 


\section{Referencias}

Alvino, J. (2004). Procesos de reflexión del Patrimonio Arqueológico desde la Actividad Arquitectónica Peruana. Revista de Investigaciones del CEAR, 6, 215-237.

Canziani, J. (24.03.2018). Paisajismo Inca. Conferencia Nacional, realizada en Auditorio Fundación Telefónica, Lima, Perú.

Dewey, J. (1948). La ciencia de la educación. Buenos Aires, Argentina: Editorial Losada.

Elías, R. (2007). Historia de la Educación. Lima: Editorial San Marcos.

Estermann, J. (1998). Filosofía andina, Estudio intercultural de la sabiduría autóctona andina. Quito, Ecuador: Ediciones Abya-Yala.

Flores Galindo, A. (1987). Buscando un inca: Identidad y utopía en los Andes. Lima, Perú: Instituto de Apoyo Agrario.

Fossa, L. (2006). Narrativas problemáticas. Los inkas bajo la pluma española. Lima: Fondo Editorial de la Pontificia Universidad Católica del Perú, Instituto de Estudios Peruanos.

Freire, P. ([1970] 1976). Pedagogía del oprimido. México: Siglo vêintiuno editores. Decimocuarta edición.

Geddes, P. (1960). Ciudades en evolución. Buenos Aires, Argentina: Editorial Infinito.

Godenzzi, J. (2005). En las redes del lenguaje. Cognición, discurso y sociedad en los Andes. Lima, Perú: Universidad del Pacífico.

Gutiérrez, M. (2013). Otra vez sobre sincretismo. En J. Sánchez y M. Curatola (Ed.), Los rostros de la tierra encantada. Religión, evangelización y sincretismo en el Nuevo Mundo. Homenaje a Manuel Marzal, S.J. (pp. 503-522). Lima, Perú: Fondo Editorial de la Pontificia Universidad Católica del Perú, Instituto Francés de Estudios Andinos.

Guzmán, M. (2003). Huarco. Arquitectura ceremonialen Cerro Azul, Lima, Perú: Universidad Ricardo Palma, Editorial Universitaria.

Guzmán, M. (2016a). Arquitectura Chancay. Espacios rituales del tiempo sagrado. Lima, Perú: Universidad Ricardo Palma, Editorial Universitaria.

Guzmán, M. (2016b). Arquitectura y paisaje simbólico en los andes centrales. Arquitextos, 31, 11-30.

Ludeña, W. (1997). Ideas y arquitectura en el Perú del siglo XX. Lima, Perú: SEMSA Servicios Editoriales Múltiples.

Ludeña, W. (2001). ARQUITECTURA, repensando a Vitruvio y la tradición occidental.
Lima, Perú: Universidad Nacional de Ingeniería, Facultad de Arquitectura, Urbanismo y ArtesInstituto de Investigaciones.

Marzal, M. (2002). Tierra encantada. Tratado de antropología religiosa de América Latina. Madrid, España / Lima, Perú: Editorial Trotta, Pontificia Universidad Católica del Perú.

Neira, E. (1962). El desarrollo regional y su vinculación con la arquitectura. El Arquitecto Peruano, 297-298-299: 21-25.

O'Phelan, S. (1999). Repensando el Movimiento Nacional Inca del siglo XVIII. En S. O'Phelan (Comp.), El Perú en el siglo XVIII. La Era Borbónica, (263-278) Lima, Perú: Instituto RivaAgüero, Pontificia Universidad Católica del Perú.

Portocarrero, G . y Oliart, P. (1989). El Perú desde la escuela. Lima, Perú: Instituto de Apoyo Agrario.

Quiroz, V. (2011). El tinkuy poscolonial. Utopía, memoria y pensamiento andino en Rosa Cuchillo, Lima, Perú: Fondo Editorial Universidad Nacional Mayor de San Marcos, Facultad de Letras Ciencias y Ciencias Humanas UNMSM.

Ramírez, B. y López, L. (2015). Espacio, paisaje, región, territorio y lugar: la diversidad en el pensamiento contemporáneo. México: Instituto de Geografía Universidad Nacional Autónoma de México.

Sobrevilla, D. (1989) Repensando la tradición nacional. Estudios sobre la filosofía reciente en el Perú. Lima: Hipatia

Sobrevilla, D. (1999). Repensando la tradición de Nuestra América. Estudios sobre la filosofía en América Latina. Lima, Perú: Fondo Editorial Banco Central de Reserva del Perú.

Souto, P. (Coord.) (2011). Territorio, lugar, paisaje. Prácticas y conceptos básicos en geografía. Buenos Aires, Argentina: Editorial de la Facultad de Filosofía y Letras Universidad de Buenos Aires.

Stein, W. (2010). Repensando el Discurso Andinista. Algunos tonos del Hemisferio Norte percibidos en la historia cultural peruana. Lima, Perú: Sur Casa de Estudios del Socialismo

Vega-Centeno, R. (Ed.) (2017). Repensar el Antiguo Perú. Aportes desde la arqueología. Lima, Perú: Instituto de Estudios Peruanos, Fondo Editorial Pontificia Universidad Católica del Perú.

Vitrubio, M. (1995). Los diez libros de la arquitectura. Madrid, España: Alianza Editorial. 1ra reimpresión de la 1ra edición. [Título original: De Architectura, siglo I, 27-23 a.C.] 